\title{
$O$ processo de construção da Fundação Estatal Saúde da Família da Bahia
}

\section{| ${ }^{1}$ João Batista Cavalcante Filho, ${ }^{2}$ Túlio Batista Franco |}

Resumo: A Fundação Estatal Saúde da Família (FESF-SUS) é uma Fundação Pública de Direito Privado, instituída após um longo processo de debates envolvendo os atores sociais que constroem o Sistema Único de Saúde (SUS) na Bahia. Foi criada para ser um organismo da administração indireta do estado e dos municípios, sem fins lucrativos, uma forma de descentralização e especialização do Estado brasileiro no intuito de prestar serviços sociais com maior eficiência e eficácia aos cidadãos. Este estudo pretende analisar o processo de construção da FESFSUS, buscando perceber os movimentos de criação de uma realidade dando voz às várias interpretaçôes possíveis por parte dos atores que constroem o SUS na Bahia. Analisa, ainda, os discursos diferentes que conformaram o surgimento da instituição, que entraram em luta por sua conformação, inclusive discursos não valorizados em documentos oficiais da instituição. A pesquisa é fruto de uma investigação qualitativa e utiliza como estratégia a análise genealógica. Este trabalho pretende extrair conceitos de uma experiência que sirvam como operadores da realidade, conceitos-ferramenta que auxiliem na construção do SUS, na efetivação da saúde como direito de todos e dever do Estado.

> Palavras-chave: administração em saúde; modernização do setor público; planejamento regional de saúde.

\author{
1 Universidade Federal de \\ Sergipe. Aracaju-SE, Brasil. \\ (joaoaracaju27@hotmail.com). \\ ${ }^{2}$ Universidade Federal \\ Fluminense. Niterói-RJ, Brasil \\ (tuliofranco@gmail.com).
}


A Fundação Estatal Saúde da Família (FESF-SUS) é uma Fundação Pública de Direito Privado instituída por 69 municípios baianos em 2009, após processo de debates envolvendo os atores sociais que constroem o Sistema Único de Saúde (SUS) na Bahia. Os movimentos para sua instituição foram iniciados em 2007, com uma nova gestão no governo e na Secretaria de Saúde do Estado da Bahia (SESAB), que estabeleceu como prioridade a expansão com qualidade da Estratégia de Saúde da Família (SESAB, 2007).

A proposta de criação da FESF-SUS foi construída pela SESAB e apresentada aos atores do SUS baiano. Diversas imagens e discursos foram se formando no processo, variando com os atores que participavam dos debates, as instituições que representavam, suas concepções e o próprio espaço onde o debate acontecia.

O presente estudo pretende analisar o processo de construção da Fundação Estatal Saúde da Família e busca perceber os movimentos de sua criação dando voz às várias interpretaçôes possíveis por parte dos atores que constroem o SUS na Bahia. Traz para a análise os discursos diferentes que conformaram o surgimento da instituição, inclusive discursos não valorizados em documentos oficiais. Há muitas interpretações sobre o papel das Fundações Públicas de Direito Privado no SUS, se seriam avanço ou retrocesso. A análise e avaliação destas instituições são necessárias para a correção de trajetórias, para trazer elementos para o debate e para a própria construção do SUS.

\section{Os desafios do SUS e a Reforma do Estado}

Dentre os vários desafios para a implementação do SUS, persistem os problemas de gestão (COELHO, 2010; PAIM; TEIXEIRA, 2010), como fragmentação, subfinanciamento, práticas clientelistas e corporativistas, além de dificuldade de aliança com setores da sociedade civil. Os avanços de uma política neoliberal de desresponsabilização do Estado complexificam este cenário. Segundo Paim e Teixeira (2010, p. 1820):

A reforma neoliberal iniciada na década passada, centrada num modelo gerencialista e na desresponsabilização do Estado para com parcela significativa dos direitos sociais conquistados, além de não resolver os problemas mencionados, criou outros com a disseminação de organizações sociais, OSCIPs, cooperativas e outras formas de ter- 
ceirização da gestão e precarização do trabalho em saúde. A polarização entre a administração direta e a desresponsabilização estatal embotou a busca de alternativas que, respeitando os princípios e diretrizes da Reforma Sanitária e do SUS, fossem capazes de superar os problemas aludidos e assegurassem efetividade, qualidade e eficiência nos serviços prestados pelo SUS.

O que se coloca para o debate é a Reforma do Estado, qual seria o seu papel em relação aos serviços sociais à sociedade e que consequências este papel pode ter nas arquiteturas jurídico-administrativas para a prestação de serviços com qualidade para a população.

Na segunda metade dos anos 90, o Ministério de Administração e Reforma do Estado (MARE), sob comando de Luis Carlos Bresser Pereira, foi o portavoz da proposta do Governo FHC ao propor um estado "gerencial, enxuto, que repassa suas tarefas produtivas e de prestação de serviços para terceiros, entidades privadas que possam conduzir estas atividades" (FRANCO, 1998).

$\mathrm{O}$ pano de fundo desta proposta é a adequação à concepção neoliberal de "Estado mínimo", adotando medidas que reduzam o papel deste a setores de onde sua atuação é exclusiva, privatizando e desregulamentando outros setores (como a saúde) para que o mercado e a concorrência lhes tragam eficiência. Nesse processo, busca reduzir a despesa pública e aumentar a eficiência da máquina estatal, favorecendo/recuperando sua capacidade de investimento, inclusive em programas sociais (FRANCO, 1998).

Para efetivar esta reforma, o MARE propõe as organizações sociais (OS), entidades públicas não estatais de direito privado com autorização legislativa para celebrar contrato de gestão com o Poder Executivo. Parte do pressuposto das ineficiências da administração pública, pela falta de autonomia, entraves burocráticos, custos mais altos e ausência de concorrência.

Segundo Franco e Pinto (2012), no contexto da reforma regressiva bresserniana, a Lei de Responsabilidade Fiscal (LRF) acaba por se transformar em mecanismo que produz limitações na expansão de atividades capital-trabalho intensivo, como é o caso da saúde, onde cerca de 70\% dos gastos são com pessoal.

\section{O contexto do Projeto Fundação Estatal}

Em 2004, o Ministério do Planejamento, Orçamento e Gestão (MPOG) constatou a necessidade de alternativa para a prestação de serviços sociais. Segundo 
Lenir Santos (2009), os estudos sobre as Fundaçôes Públicas de Direito Privado como uma alternativa para o SUS tiveram início no ano de 2005, sob demanda do Grupo Hospitalar Conceição de Porto Alegre, que objetivava transformar seus hospitais federais em autarquias de direito especial. As conclusões desse estudo levaram à proposta de criação de uma fundação governamental de direito privado. Ao expor esta concepção em seminário do Ministério do Planejamento em 2006, a ideia destas fundações recebeu o nome de Fundação Estatal.

Como produto do debate que ocorreu nos anos seguintes, o MPOG construiu o documento intitulado "O Projeto Fundação Estatal” (BRASIL, 2007), que traz seu objetivo no primeiro parágrafo: propor ajustes na gestão pública, utilizando mecanismos legais que permitissem maior autonomia sem abandonar o controle pelo Estado brasileiro.

Ainda segundo esse documento, por conta dos limites da administração pública direta, tornou-se necessário buscar um novo modelo jurídico-institucional, uma alternativa ágil, transparente e participativa para desburocratizar o atendimento às necessidades dos cidadãos. Uma instituição dentro do Estado - não significando sua criação um passo para terceirização ou privatização - que incorporasse a este, inovações, como avaliação por desempenho com metas adequadas a cada realidade, profissionalização da gestão com comprometimento de seus dirigentes com as metas pactuadas e vinculação de seus mandatos aos êxitos da gestão. E que fosse subordinada aos controles externos e internos da administração pública e ao controle social.

O Governo Federal então enviou o projeto de lei no 92/2007 ao Congresso Nacional, com o intuito de disciplinar o art. 37, XIX da Constituição Federal, que estabelece a necessidade de Lei Complementar para disciplinar os campos de atuação das fundações estatais. Posteriormente, o relator Pedro Henry apresentou projeto substitutivo, mais detalhado e extenso (SANTOS, 2009).

O Conselho Nacional de Saúde (CNS) reagiu ao envio do Projeto de Lei, alegando a não inserção da entidade no debate deste, como preconizado na legislação do SUS (CNS, 2007). No informativo, o CNS posicionava-se contrário às Fundaçôes Estatais, reconhecendo a necessidade de ampliar o debate com a sociedade civil organizada sobre as diferentes modalidades de gestão do SUS. 
Para o CNS (2012), a proposta das Fundações Estatais não é uma alternativa por dentro do Estado e há um pressuposto que a implementação do SUS somente se daria através da administração direta e do cumprimento do arcabouço legal já existente. Infere também que as Fundações Estatais necessariamente seguirão a cultura de aparelhamento de estruturas que deveriam ser públicas, a ocupação destes espaços por grupos políticos organizados, afetando o comprometimento dos profissionais e a eficiência da instituição. Algo que, afirmam, não ocorreria na administração direta.

Segundo Merhy, Franco e Pinto (2007), o debate da alternativa Fundação Estatal aparece cheio de confundimentos e em um contexto ruim, devido aos conflitos do Governo Federal com o movimento sindical relacionados à regulamentação do direito de greve do servidor público, à manipulação da mídia associando as fundações à privatização do sistema e ataque aos direitos dos servidores, e confusóes sobre o que representa o uso do termo "direito privado".

A conjuntura desfavorável e a insuficiência e aversão ao debate sobre novos modelos na administração pública, pela identificação com o projeto neoliberal, aumentavam as resistências à proposta e não houve uma condução que superasse estes entraves, fazendo com que este PLC até hoje não tenha sido votado.

Ao analisar as Fundações Estatais, Conselho Nacional dos Secretários de Saúde destaca as bases jurídicas que permitem a instituição destas e o entendimento de que são uma modalidade de descentralização administrativa, dentro da administração pública indireta, ou seja, "é administração pública, patrimônio público personalizado segundo as regras do direito privado para a prestação de serviços públicos e seus agentes são empregados públicos, revestidos de responsabilidade pública” (CONASS, 2008, p. 32).

Em documento publicado em 2010, o Conselho Nacional de Secretários Municipais de Saúde (CONASEMS) reforça seu posicionamento em defesa do SUS, mas aponta dilemas para sua implementação, relacionados ao modelo de atenção à saúde, ao financiamento, à formação e oferta de profissionais de saúde, particularmente de profissionais médicos, e à gestão pública da saúde (CONASEMS, 2010).

No mesmo documento, o CONASEMS reconhece a necessidade de reformas jurídico-administrativas para o SUS. O processo de descentralização, se não 
cercado de condições para sua implementação, cria uma situação penosa às gestões municipais, devido às amarras burocráticas que dificultam a gestão do trabalho, os processos de compras e a realização de investimentos.

Segundo o CONASEMS, para o município não cometer ilegalidades - como superar o teto da LRF ou o teto remuneratório municipal para atrair profissionais -, as terceirizações através de OS e OSCIP seriam uma opção. Mas a entidade faz alertas: há o risco de repassar uma responsabilidade que é pública para entidades privadas, e o risco de haver intencionalmente a privatização do SUS, quando a gestão estabelece o protagonismo do setor privado por questões ideológicas.

Nas entidades nacionais de trabalhadores, prevalece em posicionamentos como os da Central Única dos Trabalhadores (CUT) a ideia que as Fundaçôes Estatais são mais uma forma de terceirização e que não garantem aos trabalhadores direitos há muito conquistados. A contratação por via das Consolidações das Leis do Trabalho (CLT) seria uma precarização de vínculos e não garantiria a estabilidade necessária para segurança dos trabalhadores. As propostas de gestão por resultados e remuneração por desempenho são consideradas estratégias para facilitar demissões, devido às dificuldades de avaliar a produção em saúde através de instrumentos estruturados.

Em artigo escrito por sua secretária executiva, a CUT afirma que o projeto de criação das Fundações Estatais estaria na contramão do fortalecimento das políticas públicas. Apesar de concordar com a necessidade de rediscussão do papel do Estado e alternativas de personalidades jurídicas relacionadas ao setor público, a CUT é contrária ao Projeto de Lei das Fundações Estatais. "Criar novas figuras jurídicas com o objetivo principal da precarização do trabalho traduzida na perda da estabilidade do emprego - não é compatível com o real desenvolvimento que todos pretendemos" (DAU, 2007, p. 4).

Há uma concordância das entidades em relação aos aprimoramentos da gestão pública para avanços no SUS, mas discordâncias em relação aos mecanismos para tal. Nesse contexto, a FESF se apresenta com alternativa de ampliação da eficiência e transparência na prestação de serviços sociais por dentro do Estado, fortalecendo seu caráter público e legitimando suas ações junto a sociedade, visando contribuir para a desprivatização do Estado brasileiro, de forte histórico clientelista (FRANCO; PINTO, 2007). 
Ante as necessidades de aprimoramentos na administração pública, a possibilidade de instituir Fundações Estatais atraiu o interesse de estados e municípios, que passaram a discutir e aprovar, antes mesmo do Governo Federal, suas leis complementares e autorizativas. A Bahia foi um desses estados.

\section{Metodologia}

Optou-se por uma metodologia que extrapole a linearidade, a tendência de se unificar, de buscar identidade e coerência própria de algumas sistematizações. Extrapole a busca da origem perfeita, e que negligencie como inacessíveis conteúdos históricos.

Esta pesquisa é uma investigação qualitativa e utiliza como estratégia a análise genealógica proposta por Foucault. Segundo Faé (2004, p. 15):

Foucault entende a genealogia como uma atividade de investigação trabalhosa, que procura os indícios nos fatos desconsiderados, desvalorizados e mesmo apagados pelos procedimentos da história tradicional, na busca de conformação de suas hipóteses. A atividade genealógica requer, indispensavelmente, a busca da singularidade dos acontecimentos, sobretudo naquilo que não participa da história, como os sentimentos, o amor, a consciência, os instintos, fazendo emergir o entendimento sobre os espaços onde desempenharam papéis distintos e/ou foram excluídos do discurso verdadeiro.

Longe de buscar o encadeamento natural dos fatos, a narrativa genealógica não se apoia em constâncias e não busca contar uma história como reconciliação, uma verdade eterna. Busca analisar a emergência enquanto entrada em cena de forças em disputa. "A emergência é, portanto, a entrada em cena das forças; é a sua interrupção, o salto pelo qual elas passam dos bastidores para o teatro, cada uma com seu vigor e sua própria juventude" (FOUCAULT, 1979, p. 24).

A genealogia busca a origem dos saberes, a explicação dos aspectos que interferem em sua emergência e adequação ao campo discursivo, expondo sua existência como elementos de uma determinada construção histórica. Neste processo, o objetivo não é destruir o que existe, mas estudá-lo, analisá-lo desafiando verdades tidas como absolutas e as histórias lineares, a versão dos vencedores.

Foram utilizados como instrumentos de produção de dados a análise dos documentos oficiais da FESF - além da produção escrita sobre a instituição - e entrevistas semiestruturadas. Foram entrevistados, sempre considerando a época 
de construção da FESF-SUS, representantes da gestão estadual baiana (GES): o secretário estadual de Saúde, o diretor de Atenção Básica e um procurador jurídico da Procuradoria Geral do Estado; representantes da gestão municipal (GEM): a prefeita da cidade que teve a maior quantidade de profissionais através de serviços contratualizados com a Fundação e um secretário municipal de Saúde que era membro do Conselho de Secretários Municipais de Saúde (COSEMSBA); e duas conselheiras do Conselho Estadual de Saúde da Bahia (CES).

Nas entrevistas, os atores foram convidados a relatar seu ponto de vista sobre a criação da FESF: descrever o processo de construção da proposta, esclarecer os posicionamentos das entidades participantes, as vantagens, desvantagens e consequências da criação da FESF, e os motivos que levaram à proposição e aprovação da fundação. As entrevistas foram gravadas e transcritas, e tinham por objetivo aproximar o cenário de construção da FESF.

Para análise dos dados, buscou-se fazer uma leitura atenta dos documentos, assim como as narrativas obtidas das entrevistas. Os pontos centrais de caracterização das posições acerca da organização da FESF emitidos pelos atores envolvidos nesta ação foram devidamente observados e discutidos, considerando que havia uma multiplicidade de entidades e pessoas, e que as posiçóes e projetos para a FESF expressavam diferentes opiniōes sobre o que deveria ser a Fundação. Os dados foram discutidos e analisados considerando a matriz discursiva dos entrevistados e o que estava expresso na documentação da FESF.

Visando manter a confidencialidade do material produzido, optou-se por representar os atores através de letras que vão de "A “até "G". Os participantes foram esclarecidos dos métodos e objetivos da pesquisa e assinaram Termo de Consentimento Livre e Esclarecido. O projeto de pesquisa foi autorizado por Comitê de Ética em Pesquisa, obedecendo à Resolução no 196/96 do Conselho Nacional de Saúde.

\section{Resultados e Discussão}

\section{O processo de construção da Fundação Estatal Saúde da Família}

Após a vitória de Jaques Wagner para o Governo da Bahia em 2006, um dos focos da futura equipe da Secretaria de Saúde do Estado foi a criação de uma carreira 
estadual para a Estratégia de Saúde da Família, que garantisse direitos trabalhistas e previdenciários e possibilidade de mobilidade entre os municípios (SESAB, 2009).

Era necessário avançar na implementação da Estratégia de Saúde da Família. A Bahia era o quarto estado do Brasil em termos populacionais, o sexto economicamente e o vigésimo segundo em indicadores sociais. Segundo a FESFSUS (FESF, 2009), a Bahia apresentava alguns dos piores indicadores de acesso e qualidade de saúde da Região Nordeste, como a maior taxa de incidência de tuberculose e a mais elevada razão de mortalidade materna da Região Nordeste, entre outros indicadores sensíveis à qualificação da APS.

O diagnóstico feito pela SESAB, em conjunto com o Núcleo de Estudos em Saúde Coletiva da Universidade Federal de Minas Gerais em 2008, apontava desafios em relação à gestão do trabalho e em relação às iniquidades, pela discrepância existente entre os municípios baianos (porte, população, arrecadação). Segunda Andrade (2009, p. 41-42):

[...] o referido diagnóstico também identificou um conjunto de problemas relacionados à: insuficiência de infraestrutura e insumos, resultante do baixo investimento; dificuldade de contratação de alguns profissionais tendo em vista a existência de um mercado concorrencial entre os municípios e, por conseguinte, alta rotatividade dos profissionais e instabilidade das equipes; precarização das relações de trabalho - imposta pela ausência de uma carreira que garantisse os direitos trabalhistas e que desse conta das especificidades do trabalho na Saúde da Família nos diversos municípios baianos; reduzido investimento em educação permanente e baixa qualidade da atenção à saúde, gerando inadequação do processo de trabalho, insatisfação dos usuários e baixa resolutividade e qualidade.

Ficava clara a busca da SESAB por um modelo estatal de gestão pública, uma alternativa para contratualização com OS, que crescia em âmbito nacional. Vale ressaltar que a gestão baiana recorre aos contratos de gestão com OS e à parceria público-privada em outros âmbitos do sistema, como na atenção hospitalar (SESAB, 2013), refletindo, dentre outras análises possíveis, que não se pensa o modelo de fundações como um a priori ou ainda o único arranjo possível para o SUS.

A situação era ruim para os gestores, para os trabalhadores e para os usuários. Os secretários municipais de Saúde viviam as limitações já diagnosticadas pelo CONASS e CONASEMS, e expressa em documento da SESAB: 

da SESAB, 2007

Quebra da continuidade na prestação de serviços, pela alta rotatividade dos profissionais,
principalmente médicos e nos locais mais afastados e menores
Iniquidades - onde os municípios menores, mais afastados dos grandes centros e com
menor arrecadação necessitam gastar mais para manter o sistema, pela menor escala de
compras e salários mais altos para atrair profissionais.
Mercado predatório - na tentativa de atrair profissionais e se aproveitando da precarização
dos vínculos, municípios promovem aumentos de salários ou benefícios indiretos
(moradia, combustíveis, folgas) no intuito de atrair profissionais já contratados em outros
municípios da região
Pouco investimento na qualificação de profissionais que não consegue fixar.
Situações instáveis do ponto de visa legal, como a necessidade de exceder os limites
da LRF ou o teto remuneratório municipal, flexibilização de carga horária para atrair
profissionais médicos, e ainda contratação de profissionais através de contratos com
relaçôes precárias de trabalho.

Fonte: SESAB (2007).

Os trabalhadores enfrentavam um cenário de precarização, onde a garantia de direitos trabalhistas era uma exceção. Estudo realizado por Sábado Girardi e João Girardi (2008) diagnosticou o grau de precarização do trabalho na Bahia:

Tabela 1: Distribuição dos municípios baianos que contratam diretamente segundo formas de vínculo das profissóes de nível superior que atuam na ESF, 2007

\begin{tabular}{|c|c|c|c|c|c|c|}
\hline \multirow{3}{*}{$\begin{array}{c}\text { Forma de } \\
\text { Vínculo }\end{array}$} & \multicolumn{2}{|c|}{ Médico } & \multicolumn{2}{|c|}{ Dentista } & \multicolumn{2}{|c|}{ Enfermeiro } \\
\hline & \multicolumn{2}{|c|}{$\mathrm{N}: 200$} & \multicolumn{2}{|c|}{$\mathrm{N}: 192$} & \multicolumn{2}{|c|}{$\mathrm{N}: 204$} \\
\hline & $\mathrm{N}$ & $\%$ & $\mathrm{~N}$ & $\%$ & $\mathrm{~N}$ & $\%$ \\
\hline Estatutário & 23 & 11,5 & 14 & 7,3 & 42 & 20,6 \\
\hline CLT & 19 & 5 & 12 & 6,3 & 18 & 8,8 \\
\hline Temporário & 194 & 97 & 163 & 84,9 & 175 & 85,8 \\
\hline Autônomo & 1 & 0,5 & - & - & - & - \\
\hline Comissionado & 1 & 0,5 & 1 & 0,5 & 2 & 1 \\
\hline
\end{tabular}

Fonte: NESCON/UFMG (2008). 
Este grau de precarização demonstrava aos representantes de trabalhadores que, mesmo com posicionamento contrário de entidades nacionais, ampliar a quantidade de vínculos celetistas através da Fundação Estatal Saúde da Família não poderia ser considerado um retrocesso.

Segundo a proposta da SESAB (2007, p. 7-8), a Fundação Estatal Saúde da Família é:

[...] uma entidade jurídico-institucional sem fins lucrativos, de propriedade pública, instituída pelo Poder Público, com a obrigatoriedade de prestar serviços exclusivamente ao setor público, com autonomia gerencial, orçamentária e financeira, patrimônio próprio e receitas próprias, submetida à gestão dos órgãos de direção ou gerência, conforme disposto em seu estatuto e com personalidade jurídica de direito privado, o que lhe garante mais agilidade e eficiência.

\section{Os objetivos da criação da FESF-SUS - Visão dos atores}

A ênfase nos objetivos da criação de um mecanismo como a FESF-SUS se modifica, dependendo do ator que faz a análise do contexto. $\mathrm{O}$ entrevistado $\mathrm{B}$ busca resumir a origem da proposta da FESF:

No início do governo Wagner nós, entre outras prioridades, nos debruçamos sobre a necessidade de criar melhores condições para a ampliação do Programa Saúde da Família [...]. E, obviamente a principal dificuldade do Saúde da Família está relacionada à situação de recursos humanos e em especial da categoria médica. Então uma das necessidades diz respeito a criar a possibilidade de ter um vínculo contratual mais estável e que permitisse uma continuidade e uma carreira onde o profissional pudesse inclusive se deslocar de posto de trabalho entre os municípios [...].Nós temos também algumas barreiras, a Lei de Responsabilidade Fiscal é uma delas, ela limita os gastos de pessoal por parte dos municípios, e obviamente saúde necessariamente envolve um conjunto grande de trabalhadores a serem contratados para dar a devida cobertura. Então a Fundação também foi pensada no cenário de buscar criar alternativas para desonerar o limite de pessoal dos municípios, além de poder viabilizar a remuneração, superior ao teto salarial do município que é o salário do executivo (GES).

O entrevistado A acrescenta ao objetivo de criar uma carreira, as políticas de equidade da FESF-SUS:

Junto com isso [carreira] a Fundação traz um elemento muito importante de equidade porque a maior parte dos municípios que têm a maior dificuldade de contratar os profissionais são justamente os municípios mais pobres. [...] A isso tudo, soma-se a ideia de um desenho, um modelo de gestão que era o modelo de gestão que pensava em dar formato à gestão interfederativa (GES). 
$\mathrm{O}$ entrevistado $\mathrm{E}$ também destaca a iniquidade existente entre os municípios na implementação da APS. Existindo uma concorrência predatória, os municípios menores e mais distantes terão mais dificuldade, pois necessitarão oferecer vantagens para atrair os profissionais, principalmente os médicos, mesmo com sua menor capacidade de investimento:

Impossível um município [...] de 35 mil habitantes dar conta de construir algo sólido que qualifique, que estimule e que atraia [profissionais]. Ou seja, a grande questão de provimento e fixação de profissionais. Então nessa perspectiva, a gente vendo esse modelo administrativo como um modelo que agregasse escala para que a gente pudesse fazer provimento de fixação, qualificação da atenção básica foi no momento administrativo nosso uma grande ideia (GEM)?

A entrevistada $\mathrm{D}$ é um tanto mais pragmática em relação à necessidade do município em aderir à FESF-SUS:

A posição era de participar da Fundação e de que ela pudesse se consolidar porque o maior problema que os municípios tinham era encontrar médicos, encontrar profissionais para compor as equipes do PSF, e por conta disso para [os municípios] era muito importante ter uma entidade que pudesse disponibilizar esses profissionais (GEM).

Para a entrevistada F, o principal motivador dos gestores foi construir uma forma de contratação que não incidisse no limite imposto pela LRF. Partilhando da opinião de entidades representantes de trabalhadores em âmbito nacional, a contratação via CLT da FESF-SUS se constitui em precarização e terceirização de vínculos trabalhistas:

O posicionamento do [entidade], com relação à questão da Fundação Estatal da Saúde da Família não era uma posição apenas contra a fundação estatal. Os dirigentes da [entidade] tinham, e têm até então por princípio a defesa incondicional do concurso público como única via de acesso para os trabalhadores da saúde no SUS em nosso país[...] O que embasou [a FESF], infelizmente para nós é muito frágil, porque o secretário e os seus gestores da superintendência, de primeiro e segundo escalão, alegavam muito e alegam até hoje a questão da LRF (CES).

\section{A busca por um modelo de gestão}

Segundo Silva Jr (2011), a definição, por parte da SESAB, de um modelo de gestão para aumentar a eficiência das ações da atenção primária tinha que observar premissas como ser público, participativo, democrático, que permitisse 
o desenvolvimento interfederado da Estratégia Saúde da Família, que instituísse uma carreira para trabalhadores assegurando direitos trabalhistas e mobilidade entre os municípios da Bahia, que estabelecesse metas de desempenho como forma de ampliar a eficiência da instituição.

A ideia inicial foi criar um consórcio público como modelo de gestão, abandonada por questôes relacionadas à perda de agilidade administrativa (SILVA JR, 2011), seguida da proposta de uma instituição por parte do Governo do Estado da Bahia, passível de contratualização de serviços pelos municípios do estado.

A FESF-SUS viria a ser instituída sem o governo do Estado da Bahia como instituidor, mais uma vez com uma diversidade de visões sobre os motivos que levaram a isto, de acordo com os entrevistados: a defesa de setores dentro do governo do estado do modelo das OS; o receio de que, em sendo um dos instituidores, o governo estadual pudesse se tornar devedor de passivos trabalhistas - o que já havia ocorrido em outras experiências; receio de que a contratação destes profissionais pudesse incidir no limite da LRF para o governo; e ainda o fato de a atenção básica ser responsabilidade municipal, de acordo com a legislação do SUS.

A alternativa encontrada foi que diversos municípios instituíssem a FESFSUS, com o apoio da SESAB. Segundo Santos (2009), ainda que possa ser uma inovação, não há nenhum impedimento jurídico para a instituição de uma fundação pública de direito privado por vários entes. Os municípios interessados deveriam definir as regras principais da fundação e dispô-las em uma lei municipal, deixando os detalhes de seu funcionamento para o estatuto da instituição.

A proposta da FESF-SUS ampliava seus escopos no debater com os atores. Da centralidade de uma carreira de âmbito estadual para uma instituição que buscava atender a diferentes anseios de seguimentos dos atores do SUS: 


\begin{tabular}{|c|c|}
\hline Ator do SUS & Propostas da FESF-SUS \\
\hline Gestores & $\begin{array}{l}\text { Não perderiam o comando único doSistema. Agestão seria compartilhada } \\
\text { e interfederativa, e o estatuto e o contrato de gestão com a Fundação } \\
\text { colocariam como seus objetivos a implementação da política municipal } \\
\text { de saúde, garantindo metas para os trabalhadores com este fim. A lógica } \\
\text { interfederativa facilitaria o financiamento tripartite e a busca por novos } \\
\text { recursos, que beneficiariam principalmente - mas não exclusivamente } \\
\text { - os municípios com menos recursos. A FESF-SUS tinha a potência } \\
\text { também de realizar outros serviços, como compras centralizadas que } \\
\text { gerariam grande economia pelo ganho de escala; ou a contratação } \\
\text { e qualificação de gestores. Haveria uma perda da possibilidade dos } \\
\text { gestores indicarem os profissionais de nível superior da Estratégia de } \\
\text { Saúde da Família - prática clientelista comum em muitos municípios } \\
\text { - mas haveria um concurso público em âmbito estadual que poderia } \\
\text { reduzir a rotatividade de profissionais, principalmente do profissional } \\
\text { médico. Seria uma forma de sair de ilegalidades: salários maiores que } \\
\text { o do prefeito, flexibilidades de carga horária para atrair médicos, gastos } \\
\text { com pessoal acima do teto da Lei de Responsabilidade Fiscal. }\end{array}$ \\
\hline Trabalhadores & $\begin{array}{l}\text { O ingresso por um concurso em uma carreira com direitos trabalhistas } \\
\text { pela CLT e com direito à mobilidade eram um grande atrativo, } \\
\text { devido ao alto índice de precarização do trabalho. Havia a promessa } \\
\text { de continuidade, mesmo com as alternâncias eleitorais e investimento } \\
\text { na educação permanente dos trabalhadores. A maior crítica era a } \\
\text { defesa das entidades de trabalhadores pela contratação pelo Regime } \\
\text { Jurídico Único, e não pela CLT e o fato de não considerarem a FESF- } \\
\text { SUS como parte do Estado, e sim uma terceirização. As metas para } \\
\text { os trabalhadores são considerados pelos propositores da FESF-SUS } \\
\text { um meio para eficiência e reconhecimento por iniciativas, e pelos seus } \\
\text { opositores uma forma de facilitar demissões. }\end{array}$ \\
\hline Usuários & $\begin{array}{l}\text { As promessas é que uma instituição interfederativa seria mais forte, } \\
\text { estável e eficiente, favorecendo a ampliação e melhor distribuição de } \\
\text { recursos para a qualificação da assistência à saúde. Garantiria também } \\
\text { menos rotatividade de profissionais, favorecendo a longitudinalidade e } \\
\text { a formação de vínculos. Ampliaria o acesso. }\end{array}$ \\
\hline
\end{tabular}

Fonte de dados: elaboração própria, com base no arquivo de documentos da SESAB e FESF-SUS de 2007 a 2011. 
Mas de onde viriam os recursos para instituir a FESF-SUS? A contratualização com os municípios só teria início após haver uma sede equipada e uma diretoria instituída e remunerada. Seriam utilizados recursos da Compensação de Especificidades Regionais (CER).

A CER é uma das estratégias nacionais que compõem o Piso de Atenção Básica (PAB) Variável. O PAB Variável representa a fração de recursos federais para o financiamento de estratégias nacionais de organização da atenção básica, visando superar desigualdades regionais e promover a equidade na Atenção Básica (CONASS, 2011).

O componente I da CER instituído pela Comissão Intergestores Bipartite na Bahia (CIB-BA) foi o Programa de Instituição Interfederada da Fundação Estatal Saúde da Família. Este componente representava um valor de aproximadamente nove milhões de reais, segundo portarias ministeriais e resoluções da CIB-BA de 2007 (SESAB, 2008). Este recurso da CER constituiria seu patrimônio inicial da FESF-SUS, garantiria a instituição e suas políticas de equidade, baseada em subsídios para os municípios menores e com maior dificuldade de atração dos profissionais (onde os valores de serviços em gestão compartilhada eram mais elevados).

\section{A emergência da FESF-SUS}

As articulações e debates realizados pelos gestores da SESAB chegaram à instituição da FESF - SUS (FESF, 2009) e seguiu o seguinte cronograma:

\section{Quadro 3. O processo de construção da Fundação Estatal Saúde da Família}

Primeiro Semestre de 2007 - formulação do projeto por parte da SESAB, que propõe que as Fundações Estatais sejam consideradas um dos modelos de gestão do SUS na Bahia.

Segundo Semestre de 2007 - aprovação das Fundações Estatais com um dos modelos de gestão do SUS na Comissão Intergestores Bipartite, Conselho Estadual de Saúde e Conferência Estadual de Saúde da Bahia.

Novembro de 2007 - é composta uma comissão paritária no âmbito do Conselho Estadual de Saúde com o objetivo de analisar um Projeto de Lei Complementar a ser enviado à Assembleia Legislativa da Bahia para disciplinar as Fundações Estatais no Estado.

continua... 
Dezembro de 2007 - é aprovada a Lei Complementar Estadual que disciplina as Fundações Estatais na Bahia. A Assembleia aprovaria posteriormente as Leis Autorizativas da Fundação Estatal Saúde da Família e da Fundação BahiaFarma.

No ano de 2008, muitos debates para a aprovação de leis autorizativas em âmbito dos municípios, para que estes pudessem fazer parte da gestão interfederada junto à FESF-SUS.

Em 04 de maio de 2009, de todos os municípios que já tinham aprovado suas leis autorizativas em suas respectivas Câmaras de Vereadores, 69 conseguiram enviar a tempo toda a documentação exigida pelo Ministério Público e Cartório de Pessoa Jurídica e firmaram a Escritura Pública da Fundação Estatal Saúde da Família - FESF e tornaramse coinstituidores desta Fundação.

No dia 09 de julho de 2009, após parecer favorável do Ministério Público da Bahia, a FESF foi finalmente registrada em Cartório e passou a existir no mundo jurídico.

Fonte: FESF-SUS/BA (2009).

As expectativas dos atores do SUS eram diferentes, o que fazia com que as propostas dos atores e suas entidades tensionassem os rumos da instituição que surgia:

[...] a primeira grande consequência que a gente esperava [com a FESF-SUS] seria a gente poder, pela escala, conseguir consolidar uma carreira. A segunda grande consequência seria a gente tentar regular o mercado para provimento e fixação de profissionais médicos. A terceira consequência esperada da Fundação seria o ganho em escala para compras, prestação de serviço, enfim, uma série de medidas que a Fundação poderia executar com mais agilidade que a gestão pública poderia executar para gente. (Entr.E - GEM).

Para a entrevistada D, ingressar na gestão compartilhada da FESF-SUS significaria um importante avanço no provimento de profissionais, que reduziria o risco de solução de continuidade na prestação de serviços na atenção básica municipal:

As vantagens que para o município se precisasse fazer uma substituição de algum profissional teria outro para ser substituído de forma mais célere e, portanto, não haveria nenhuma quebra de continuidade de serviços. Depois haveria uma certa facilidade para contratação na medida em que para a maioria fazer concurso demoraria muito mais tempo (GEM).

$\mathrm{O}$ entrevistado $\mathrm{C}$ defende que a FESF-SUS tem em seu cerne a lógica interfederativa, em rede, que poderia além de ganhar escala, compartilhar problemas e soluções, mais difíceis de serem encontradas pelos entes isoladamente: 
A Fundação criou uma plataforma de gestão que de alguma maneira tem uma potên-

cia de acabar com a pulverização da distribuição desses recursos, para que ela pudesse ganhar em escala e pudesse compartilhar os instrumentos de gestão com o município. Então ao invés de tirar a autonomia do município ele estava dando ferramentas para exercer a política de saúde [...]. E a Fundação teve essa potência. E acho que vai ter mais, porque as pessoas estão se apercebendo agora do tamanho, da potencialidade que ela tem [...]. Porque se você tivesse feito toda essa pactuação política, talvez você tivesse mais recurso para o projeto, porque realmente foi pífia a quantidade de recurso, assim era um projeto com essa envergadura, quer dizer, um projeto que se pressupõe a regularizar a forma da mão de obra da Saúde da Família em todo o estado é um projeto, não é pouco dinheiro. Não existe, fez milagre na verdade (GES).

Os recursos para se criar esta plataforma de gestão foram os da CER e dos contratos de gestão com os municípios. Muitas promessas de novos recursos surgiram, federais e estaduais, mas não se efetivaram no início da instituição. Os municípios ansiavam pelo que chamavam de "dinheiro novo" para a atenção básica. Houve todo o apoio político do governo do estado e da SESAB, o que garantiu a própria existência da FESF-SUS. O Estado da Bahia também era à época um dos poucos que contava com recurso estadual de incentivo à Estratégia de Saúde da FAMÍLIA, no valor de R \$ 1.500,00 (mil e quinhentos reais) por equipe. Mas os recursos estaduais específicos para a instituição só ingressavam na FESF-SUS na mesma lógica dos municípios: a prestação de serviços em gestão compartilhada. O instrumento para esta prestação é o Contrato de Programa realizado entre a SESAB e a FESF-SUS.

Aspectos relacionados à arquitetura financeira da FESF-SUS prejudicavam sua sustentação, sendo os principais motivos:

i) Não havia previsão de repasse diretamente dos recursos da CER Ministério da Saúde para a Fundação. Em não sendo um ente federado, a FESF-SUS não é portadora de fundo de saúde; em não havendo previsão de repasse dos recursos federais da CER diretamente para FESF-SUS e pelo fato de o governo do estado não ser um dos instituidores desta, o recurso da CER foi distribuído aos municípios que possuíam lei autorizativa para instituição, para que posteriormente repassassem por decreto o valor para a FESF.

ii) Houve certa liberdade para os municípios definirem a faixa de serviços, de acordo com as 11 faixas estabelecidas pela FESF-SUS para a contratualização da gestão compartilhada. Isto modificava o valor contrato, do subsídio 
e o valor da remuneração dos profissionais (quanto mais baixa a faixa, maior o salário dos profissionais, maior o valor do contrato e maior o valor do subsidio). Muitos municípios estabeleceram faixas de contrato que implicavam salários abaixo dos praticados pelo mercado na sua região.

iii) Por conta dos custos da desprecarização dos vínculos de trabalho onde agora incidiriam impostos e direitos trabalhistas - os municípios teriam dificuldades de contratualizar com a FESF-SUS. A análise feita era que, se estes custos ficassem exclusivamente na responsabilidade dos municípios, o número de associados em gestão compartilhada seria muito pequeno. A saída encontrada foi subsidiar os contratos, reduzir o valor destes utilizando o recurso da CER. Ou seja, o Contrato de Gestão com os municípios tinha um valor inferior ao custo deste. Nesta arquitetura, há um limite da Fundação para efetivar os subsídios, trazendo um cenário contraditório: quanto maior o número de contratantes, mais recurso seria necessário para os subsídios.

iv) Em caso de dificuldades, de qualquer ordem, em cumprir os compromissos financeiros assumidos pela municipalidade, o mais comum seria protelar o pagamento do que trouxesse menos consequências para a administração. Se associarmos a este fato à ideia de que a Fundação era uma instituição do governo do estado, é possível explicar a grande inadimplência que se observou. Havendo dificuldades de honrar a transferência de recurso da CER ou mesmo o valor estipulado no Contrato de Gestão, as relaçôes políticas com os municípios contratantes e o discurso de defesa da carreira e segurança para o trabalhador impediam a FESF-SUS de romper contratos ou executar débitos no âmbito judicial. A inadimplência da Fundação chegava a percentuais comprometedores de sua saúde financeira. Recuperando documentos da instituição, é possível constatar o incremento da inadimplência nos primeiros anos da instituição, passando de $70 \%$ de contratos de gestão inadimplentes, no ano de 2011.

$\mathrm{O}$ entrevistado A descreve assim a situação:

A gente apostou muito numa certa consciência interfederativa, mais estatal a longo prazo e não aconteceu. A associação que eles fazem é que como era o governador Jaques Wagner que falava da Fundação, [ela era] uma Fundação do [Governo do] estado. Então qual o raciocínio infelizmente que as pessoas fizeram: "Olha, vamos fazer o seguinte, eu estou apertado aqui, eu tenho que pagar fornecedor, eu tenho que 
pagar isso, pagar aquilo, vamos atrasar o problema da Fundação, na pior das hipóteses

depois a gente negocia com o governador". Então, por exemplo, período eleitoral todo mundo parou de pagar a Fundação (GES).

Os contratos de gestão junto aos municípios da Bahia começaram a ser rescindidos e seus trabalhadores, ou rescindiam o contrato de trabalho em conjunto ou tinham seus contratos suspensos, por falta de posto de trabalho. Compunham este cenário a inadimplência e o processo eleitoral de 2012. Devido ao seu pequeno tamanho inicial e tendência de diminuição, a FESF-SUS não conseguiu atuar na regulação do mercado de trabalho.

Ocorreu então que os serviços prestados à SESAB passaram a substituir os contratos de gestão e a CER como principal fonte de recursos da instituição, já que aqueles recursos oriundos dos serviços prestados, contratualizados pelo Contrato de Programa, contribuíam para o Fundo Administrativo da Fundação.

Pelos dados levantados na sede da FESF SUS, o Contrato de Programa representou no ano de 2012, 56,6\% do total faturado pela instituição. No ano de 2015, no primeiro quadrimestre, o valor do Contrato de Programa representava $80,42 \%$ deste total.

O entrevistado E divide sua leitura do processo atual da FESF-SUS:

A Fundação está se tornando um instrumento administrativo mais eficiente do que o estado, para operar interesses do estado e muito pouco os interesses do município. Para você ter ideia hoje a carreira, que foi um dos grandes motes da Fundação, o provimento e fixação do profissional médico isso não está mais na pauta principal. [...] Acho que a inadimplência que foi um dos principais problemas que a Fundação encontrou nos últimos anos não teve o subsídio do estado na cobrança[...] Então eu acho que existem três coisas que na Fundação hoje precisaria realmente tu olhar com mais carinho: $\mathrm{O}$ resgate da atenção básica como foco principal olhando a questão da carreira e do provimento dos profissionais; o outro, rever estruturalmente o modelo de contrato que ela faz com as prefeituras na perspectiva de que os repasses precisam ser automáticos para que a inadimplência diminua. E, por último eu acho que a reestruturação que ela está passando hoje ela precisava acontecer, mas ela precisava acontecer de forma mais coletiva, escutando mais os municípios e não os interesses do estado, voltar a ter o coletivo dos municípios. E não só os 69, e sim os 417 como os principais pautadores de suas ações e não o governo do Estado (GEM).

A FESF-SUS contava, em maio de 2015, com somente cinco municípios contratualizados, através de contrato de gestão, para a execução dos serviços assistenciais e de gestão voltados para as atividades da Estratégia de Saúde da Família, contando com 107 profissionais para estas funções. Destes, 67 são 
profissionais em pós-graduação (residência multiprofissional) de diferentes categorias que atuam na cidade de Camaçari.

Diversificou suas atividades para os serviços constantes no Contrato de Programa com a SESAB: Internação Domiciliar, Regulação, Apoio Institucional, Hospitais de Pequeno Porte, projetos e obras. As atividades do Contrato de Programa contam com 916 profissionais.

Em maio de 2015, a FESF-SUS tinha recebido somente $62,57 \%$ do total faturado relativo ao Contrato de Programa, que como dito, representa cerca de $80 \%$ do faturamento da instituição. Diversificar serviços e contratantes é uma das metas da FESF-SUS, no intuito de ampliar sua autonomia.

\section{Conclusões}

De sua origem como objetivo de criar uma carreira para a atenção básica para todos os municípios do estado, a Fundação Estatal Saúde da Família da Bahia passou por um longo processo de debates, onde as mais variadas interpretações sobre o que se apresentava foram tomando corpo, e constituindo projetos para a instituição que emergia. Há limitaçôes ao se tentar classificar estas visões, pois mesmo dentro de um mesmo seguimento há diferentes opiniōes.

Para seus propositores a FESF-SUS é um ente público, de administração indireta do Estado. Sua origem, governança e financiamento são públicos. Teria a potência, assim, de se constituir como uma alternativa para o processo de privatização e terceirização do Sistema de Saúde, na lógica neoliberal. Para seus opositores, uma instituição privatizante, sujeita ao aparelhamento e desvios pela falta de transparência, e sujeita à desresponsabilização da gestão pública direta, com prejuízo aos direitos dos trabalhadores. Extremos que se expressaram em diferentes intensidades em sua construção.

No processo baiano, os contratos de gestão da Estratégia de Saúde da Família remunerados pelos municípios e o recurso da CER repassados pelo Ministério da Saúde não foram suficientes para a saúde financeira da instituição. Foi preciso diversificar os serviços e a Secretaria Estadual de Saúde da Bahia se transformou na principal contratante da FESF-SUS, através de um Contrato de Programa. A Fundação assumiu o papel de um importante ente executivo de projetos da SESAB, mas isto não afetou a constante inadimplência no pagamento de seus serviços. 
O surgimento da FESF-SUS buscou inovar a gestão do SUS no Estado da Bahia. Provocou intenso movimento legislativo relacionado à saúde e foi a primeira carreira de âmbito estadual para a Estratégia de Saúde da Família (FESF, 2009). Possui Plano de Empregos Carreira e Salários que visava garantir segurança para seus trabalhadores - segurança esta que não se efetivou - e implementar lógicas de gestão por resultados e remuneração variável. A lógica interfederativa construída teria a potência de ser um arranjo sistêmico que facilitasse a busca coletiva da superação dos desafios na implementação da APS e de ser um instrumento de desprivatização do Estado brasileiro.

No entanto, para a potência deste arranjo sistêmico se efetivar, uma instituição como a FESF-SUS necessitará não somente de financiamento compatível, mas também de instrumentos que regulem a relação entre os entes, para além do estruturado em contratos de gestão, sob o risco de tais relações não se sustentarem frente às alternâncias do campo governamental; e de instrumentos que reforcem a participação e a democratização de sua gestão, em prol de sua transparência e resistência à colonização de interesses corporativos.

O projeto hegemônico na FESF-SUS hoje se baseia no papel da instituição como executora de políticas da Secretaria Estadual de Saúde da Bahia, claramente demonstrado pelo número de municípios que contratualizam com a FESF em maio de 2015, e o aumento na participação da sua sustentação, dos contratos por programas. Porém, esses projetos ainda estão em disputa no âmbito da instituição. O compartilhamento e maiores estudos sobre a experiência da FESF-SUS podem tanto mudar (novamente) os rumos da instituição como mostrar caminhos para a defesa dos princípios do SUS. ${ }^{1}$

\section{Referências}

ANDRADE, L. R. de. A FE no SUS: Fundação Estatal como proposta de gestão do trabalho para a Estratégia Saúde da Família na Bahia. 2009, 128 f. Dissertação (Mestrado). Escola Nacional de Saúde Pública Sergio Arouca. Rio de Janeiro, 2009.

BRASIL. Ministério do Planejamento, Orçamento e Gestão. Projeto Fundação Estatal: principais aspectos. Brasília-DF: MPOG, 2007.

COELhO, I. B. O ocaso da Reforma Sanitária Brasileira. Rev. Saúde em Debate. Rio de Janeiro, v. 34, n. 87, p. 647-657 out/dez 2010. 
CONSELHO NACIONAL DE SAÚDE. Conselho Nacional de Saúde é contra as Fundaçôes Públicas de Direito Privado. Brasília, 2009. Disponível em: http://www.conselho.saude.gov. br/informativo/2009/20/informe_20.htm Acesso em: 25 set. 2012.

Fundação Estatal: entenda o posicionamento do Conselho Nacional de Saúde. Jornal do CNS. Brasília, ano 3, ed. esp., nov. 2007.

CONSELHO NACIONAL DE SECRETÁRIOS DE SAÚDE. Gestão e Financiamento do Sistema Único de Saúde. Brasília: CONASS, 2008.

. Atenção Primária e Promoção da Saúde. Brasília: CONASS, 2011, 197p. (Coleção para entender a gestão do SUS).

CONSELHO NACIONAL DOS SECRETÁRIOS MUNICIPAIS DE SAÚDE. Tese do CONASEMS 2010/2011. Brasília: CONASEMS, 2010.

DAU, D. M. Fundações estatais: na contramão da valorização dos serviços públicos. São Paulo, 2007. Disponível em: <http://www.cut.org.br/ponto-de-vista/artigos/3843/fundacoesestatais-na-contramao-da-valorizacao-dos-servicos-publicos>. Acesso em: 30 nov. 2012.

FAÉ, R. A genealogia em Foucault. Rev. Psicologia em Estudo. Maringá, v. 9, n. 3, p. 409416, set/dez. 2004.

FOUCAULT, M. Microfísica do poder. Rio de Janeiro: Graal, 1979.

FRANCO, T. B.; PINTO, H. A. Fundaçôes Estatais como dispositivo para a desprivatização do Estado brasileiro. Disponível em: http://www.professores.uff.br/tuliofranco/textos/ fundacoes-estatais-desprivatizacao-estado.pdf. Acesso em: 06 set 2012.

FRANCO, T. B. As Organizaçôes Sociais e o SUS. 1998. Disponível em: http://pt.scribd.com/ doc/39010766/Organizacoes-Sociais-e-o-SUS-Tulio-Franco>. Acesso em: 06 out. 2013.

FUNDAÇÃO ESTATAL SAÚDE DA FAMILIA. A Bahia Unida por um novo caminho para a Saúde da Familia. Salvador, 2009

GIRARDI, S. N.; GIRARDI JUNIOR, J. B. Resultados preliminares: Saúde da Família na Bahia. Belo Horizonte: NESCON/UFMG, 2008.

MERHY, E. E.; FRANCO, T. B.; PINTO, H. A. Fundação Estatal e o fortalecimento da capacidade de ação do Estado. Disponível em: <http://www.planejamento.gov.br/secretarias/ upload/Arquivos/seges/fundacao_estatal/artigos/080703_PFE_Art_fortalecimento.pdf>. Acesso em: 06 set 2012.

PAIM, J. S.; TEXEIRA, C. F. Configuração Institucional e Gestão do Sistema Único de Saúde: problemas e desafios. Ciência \& Saúde Coletiva. Rio de Janeiro, v. 12, sup., p. 18191829, 2007.

SANTOS, L. (Org.). Fundaçôes Estatais: estudos e parecer. Campinas: Saberes, 2009. 
SECRETARIA DA SAÚDE DO ESTADO DA BAHIA. Fundação Estatal Saúde da

Família: proposta preliminar para debate. Salvador: SESAB, 2007.

. Plano Estadual de Saúde 2007-2010. Revista Baiana de Saúde Pública. Salvador, v. 33, supl. 1, nov. 2009.

Secretaria da Saúde do Estado da Bahia. Disponível em: <http://www.saude. ba.gov.br/dgrp/index.php?option =com_content \&view=frontpage \&Itemid=34>. Acesso em: 25 mai. 2013.

. Nota Técnica 02/2008. Salvador: SESAB, 2008.

SILVA JUNIOR, A. C. da. A gestão compartilhada, colaborativa, participativa e interfederada da Estratégia de Saúde da Família - a experiência da Fundação Estatal Saúde da Família da Bahia. In: MODESTO, P.; CUNHA JUNIOR, L. A. P. (Org.). Terceiro Setor e parcerias na área de saúde. Belo Horizonte: Fórum, 2011, p. 213-246.

\section{Nota}

${ }^{1}$ J. B. Cavalcante Filho realizou a coleta e a análise de dados da pesquisa, redigindo o artigo na sua totalidade. T. B. Franco contribuiu na orientação do artigo e participação na redação final. 


\section{Abstract}

\section{The building process of the Family Health State} Foundation of Babia, Brazil

The Fundação Estatal Saúde da Família (FESF-SUS)

is a Public Foundation. It has been established after a

long process of discussions involving social actors that comprise the National Health System [Sistema Único de Saúde-SUS] in Bahia. Its main goal is to act as a form of decentralization and specialization of the Brazilian State to provide social services that are more efficient. This study aims to analyze the process of building the EFSFSUS, seeking to realize the creation of a reality giving voice to several possible interpretations by the actors who build the SUS in Bahia. It reflects upon the different discourses that have shaped the institution's creation, and the ones that struggled for its conformation, taking into account the speeches that were not valued in the official documents of the institution. This research is the result of a qualitative research and uses the genealogical analysis strategy proposed by Foucault. This paper intends to extract concepts from an experience that will serve as the reality operators concepts tool to assist in the construction of SUS, in the realization of health as a right of all and duty of the State.

> Key words: health management; modernization of the public sector; regional health planning. 